\title{
Personel sqdu grodzkiego w Sieradzu za starosty Jana Koniecpolskiego (1442-1455)
}

\section{Das Personal des Kreisgerichtes in Sieradz zur Zeit des Starosten Jan Koniecpolski (1442-1455)}

1. Nominacja Jana Koniecpolskiego na urząd starosty sieradzkiego. 2. Wybór burgrabiego i rządcy. 3. Osobiste sądy starosty. 4. Organizacja sądu grodzkiego. 5. Ludzie sprawujący sądy: pochodzenie i stan majątkowy. 6. Asesorowie.

1. Die Berufung yon Jan Koniecpolski ans Starostenamt in Sieradz. 2. Burggraf- und Burgverwalterwahl. 3. Persönliche Gerichtsverfahren des Starosten. 4. Organisation des Kreisgerichtes. 5. Menschen, die die Gerichtsverhandlungen abgehalten hatten: Herkunft und Besitzstand. 6. Assessoren.

1. Kanclerz królestwa Jan Koniecpolski objął starostwo sieradzkie po Piotrze Szafrańcu III z Pieskowej Skały, który po raz ostatni z tym tytulem wymieniony został 11 kwietnia 1442 r. Ksieggi grodzkie sieradzkie z okresu jego urzędowania kończą się na wpisach z 1 stycznia 1442 r., księgi zaś jego następcy Koniecpolskiego rozpoczynają się od stycznia (pierwsza datowana wzmianka 3 I) 1443 r. ${ }^{1}$ Nominacje otrzymał Jan z rąk króla Wladysława III na Węgrzech, u którego boku przebywał od początku wyprawy po koronę węgierską ${ }^{2}$. Ingres na urząd odbył Koniecpolski z opóźnieniem, pierwsza jego obecność na

${ }^{1}$ Urzędnicy lęczyccy, sieradzcy $i$ wieluńscy XIII-XV wieku. Spisy, opr. J. Bieniak, A. Szymczakowa, red. A. Gąsiorowski, Wrocław 1985, nr B 359, B 360; AGAD, Ksieggi grodzkie sieradzkie [dalej: SG], ks. 7, s. 135; ks. 8, s. 4.

${ }^{2}$ Dokumentacja dotyczy Jana Koniecpolskiego od 10 kwietnia 1442 r.: ZDM, wyd. S. Kuraś, I. Kurasiowa, cz. III-VIII, Wrocław 1969-1975; cz. III, nr 605, 612, 617, 620, 622, 626, 628, 633; cz. VIII, nr 2370, 2403, 2425, 2427, 2438; Materialy do historii miasta Sambora 1390-1795, wyd. A. Dörflerówna, Lwów 1936, nr 12; Muzeum Narodowe w Krakowie, Biblioteka Czartoryskich, Teki Naruszewicza, t. 17, nr 135, 156, 160, 166; KDWp, t. X, wyd. A. Gąsiorowski, T. Jasiński, Poznań 1993, nr 1586, 1590, 1597, 1598; Akta grodzkie i ziemskie z czasów Rzeczypospolitej polskiej z Archiwum tak zwanego bernardyńskiego we Lwowie, wyd. K. Liske, 1. Il, Lwów 1870, nr 66; t. VI, Lwôw 1876, nr 20; KDP, wyd. L. Rzyszczewski, A. Muczkowski, J. Bartoszewicz, t. II-III, Warszawa 1848-1858; t. II, nr 587, 588; t. III, nr 212. 
posiedzeniu sądu grodzkiego w Sieradzu poświadczona została dopiero 5 marca 1444 r. Już jednak od 6 listopada 1442 r. w jego imieniu na roczku sieradzkim zasiadał stolnik łęczycki Klemens z Bechcic, z tytułem vicecapitaneus ${ }^{3}$.

2. Koniecpolski, zajęty działalnością publiczną, musial wyznaczyć na swych pelnomocników osoby godne zaufania, zdolne zastąpić go $w$ terenie $w$ okresach długotrwałej absencji. Trudno powiedzieć, czy wybral ich spośród Sieradzan towarzyszących mu na wyprawie węgierskiej, czy też przekazal swe pelnomocnictwa osobom przebywającym w kraju, ale wcześniej dobrze sobie znanym. Wybór starosty padł bowiem na sąsiada - Jana z Rogaczewa, któremu powierzył funkcję prokuratora, czyli rządcy dóbr królewskich, oraz na Andrzeja ze Zduńskiej Woli, któremu przekazal urząd burgrabiego. W przeciwieństwie do swych poprzedników, zwłaszcza starostów Mikolaja z Michałowa (1406-1418) i Piotra Szafrańca I (1418-1436), którzy dzielili obowiązki związane $\mathrm{z}$ funkcjonowaniem starostwa między liczny personel, dobrze nam znany $\mathrm{z}$ racji poświadczeń uczestnictwa $\mathrm{w}$ posiedzeniach sądowych ${ }^{4}$, za Koniecpolskiego dochodzi do centralizacji władzy w ręku wymienionych osób. Jej zakres i odpowiedzialność ludzi starosty były duże, zważywszy że Koniecpolski w ciągu dziewięciu lat (1444-1453) osobiście przewodniczyl posiedzeniom sądowym zaledwie $32 \mathrm{razy}^{5}$.

3. Koniecpolski zjeżdżal do Sieradza nieregularnie, a wizyty te $z$ reguly łączyły się $z$ terminami zjazdów generalnych w Sieradzu i Piotrkowie. Sesje sądowe pod przewodnictwem starosty miały uroczysty charakter. Świadczy o tym skład tych sądów. U boku starosty zasiadali wówczas liczni urzędnicy ziemscy sieradzcy. Najczęściej Koniecpolskiemu towarzyszyli: podstoli Jakub z Dąbrowy Wielkiej (9 razy), podsędek Mikolaj z Grabna (7), podkomorzy Piotr Zajączek z Wrzącej (6), pisarz Andrzej Wężyk z Woli (6), sędzia Mszczuj z Rokszyc (4), kasztelan sieradzki Wawrzyniec z Kalinowej (2), kasztelan rozpierski Hincza z Rogowa (2) i kasztelan spycimierski Jan z Grąd (2). Pojedynczo zaszczytu udziału w sądownictwie starosty doznali:

${ }^{3}$ SG, ks. 8, s. 271; AGAD, Ksiegi ziemskie sieradzkie [dalej: SZ], ks. 11, k. 45v.

${ }^{4} \mathrm{Z}$ tego czasu znamy: burgrabiów, sędziów i podsędków grodzkich, pisarzy, prokuratorów, seniorów grodu, justycjariuszy. O współpracownikach starostów wielkopolskich zob. A. G ąsiorowski, Urzędnicy zarzq̨du lokalnego w późnośredniowiecznej Wielkopolsce, Poznań 1970 , s. $261-327$.

${ }^{5} \mathrm{SG}, \mathrm{ks.} 8$, s. $271,360,558,580,591,594,598,599,604,676,777$; ks. 9 , s. $31,48,336$, $338,347,349,358,368,506,562,563,728,746,846,860$; ks. 10, s. $108,112,203,207$, $758,1043$. 
wojski większy Stanisław z Majaczewic i miecznik Mikołaj z Woźnik. Starosta widział chętnie u swego boku także urzędników innych ziem, jak wojewodę łęczyckiego Wojciecha Malskiego (5 razy) i stolnika lęczyckiego Klemensa z Bechcic (3). Obaj byli także ziemianami sieradzkimi, właścicielami dóbr położonych niedaleko Sieradza. Nie wiadomo natomiast, czy Klemens nadal pełnil obowiązki zastępcy starosty, bowiem poza wskazaną wyżej sytuacją brak potwierdzenia $w$ źródłach sprawowania przezeń tej funkcji.

4. Organizację i ustrój sądów grodzkich w Sieradzkiem w ogólnym zarysie omówil S. Kutrzeba ${ }^{6}$. Przyjrzyjmy się bliżej funkcjonowaniu sądu grodzkiego w Sieradzu w $1443 \mathrm{r}$. Jak wspomniano, starosta nie pojawil się $w$ tym roku ani razu w Sieradzu, w którym odbyly się w tym czasie 104 posiedzenia sądu. $Z$ reguły sąd zbieral się co trzy dni i obradował przez jeden dzień. Najczęściej sesje przypadały na poniedziałek (36) i piątek (20), rzadziej we wtorek (13), środę, sobotę (po 11), czwartek (9). Czterokrotnie sąd zebral się w niedziele: 26 maja, 8 lipca, 22 i 29 września ${ }^{7}$. Terminy poniedziałkowe związane byly $\mathrm{z}$ odbywającymi się $\mathrm{w}$ tym dniu cotygodniowymi targami. Dla niedzielnych nie znajdujemy wyjaśnienia. Na niedziele te nie przypadały ani ważne uroczystości religijne, ani jarmarki, kiedy to można było spodziewać się większych zgromadzeń w Sieradzü.

5. Sprawne funkcjonowanie sądu zależało od ludzi. W ciągu $1443 \mathrm{r}$. w sądzie zasiadalo aż 112 osób. Najczęściej byli obecni: Andrzej ze Zduńskiej Woli (poświadczony 44 razy), Jaroslaw z Zagórzyc (26), Jan Rogaczewski (19) i Jakub z Pągowa (17). Przyjrzyjmy się bliżej tym osobom.

Andrzej ze Zduńskiej Woli - burgrabia i sędzia grodzki, w latach 1443-1454 opuścil jedynie $6 \%$ posiedzeń sądowych. Pochodzil $\mathrm{z}$ rodu Dolęgów, z rodziny urzędniczej z Lęczyckiego. Był synem Piotra i Siechny z Bierzwiennej - córki Stefana i Orgaszki, wnukiem miecznika Andrzeja9. Piotr również często zasiadał jako asesor $w$ sądach sieradzkim i szadkowskim w latach 1417-1427 i zapewne wprowadzil syna w arkana prawa. Andrzej

${ }^{6}$ S. Kutrzeba, Sądy ziemskie i grodzkie w wiekach średnich, Kraków 1901, s. 103-107.

${ }^{7} \mathrm{SG}$, ks. 8, s. 100, 139, 166, 169.

${ }^{8}$ Kościół parafialny miał wezwanie Wszystkich Świętych, dominikański św. Stanisława. Jarmarki w Sieradzu odbywały się w pierwszą niedzielę po Zielonych Świątkach (w $1443 \mathrm{r}$. - 16 czerwca) i w dzień Wszystkich Świętych (1 listopada) - zob. R. R osin, Miasta do 1572 r., [w:] Szkice z dziejów Sieradzkiego, red. J. Śmiałowski, Łódź 1977, s. 75, 78.

" W 1417 r. Siechna - żona Piotra ze Zduńskiej Woli, z siostrą Spiechną - żoną Jana z Sẹdzic, sprzedały swą macierzyznę w ziemi sieradzkiej braciom Mikołajowi i Piotrowi z Bierzwiennej - AGAD, Ksiegi ziemskie szadkowskie [dalej: SzZ], ks. 1, k. 24. 
początkowo związal się z Mszczujem z Rokszyc - podsędkiem, następnie sędzią sieradzkim, u którego rozpocząl slużbę co najmniej od czerwca 1440 r. i pełnil ją do 22 marca 1451 r., czyli do śmierci sędziego. Zastẹpowal Mszczuja jako jego komornik przewodnicząc posiedzeniom sądowym w Sieradzu i Szadku ${ }^{10}$. Prawdopodobnie to właśnie sędzia polecil go swemu krewnemu Koniecpolskiemu. Andrzej po raz pierwszy odnotowany został z urzędem sędziego grodzkiego 7 stycznia $1443 \mathrm{r}$. Tytulatura jego zapisywana była bardzo różnie: iudex, iudex castri, commissarius iudex, commissarius iudex castri Siradiensis. Nieco później (10 września 1443 r.) odnotowano go z urzędem burgrabiego ${ }^{1}$. Oba urzędy otrzymał jednocześnie. Rozbieżność w czasie wytłumaczyć można specyfiką źródeł. Dla pisarza sądowego ważniejsza była jego godność sędziego. Na tym właśnie polegała reorganizacja służb starościńskich za Jana Koniecpolskiego. Połączył on dwa samodzielne dotąd urzędy w jednym ręku. Czasami kumulację tę oddawano w tytulaturze Andrzeja: burgrabius et iudex commissarius Siradiensis ${ }^{12}$. Kompetencje nowego urzędnika rozciągały się na powiaty sieradzki i szadkowski ${ }^{13}$. Przyglądając się itinerarium Andrzeja, można stwierdzić, że sądownictwo ziemskie i grodzkie na tym terenie $i \mathrm{w}$ tym okresie spoczywało niemal wyłącznie $w$ jego ręku.

Majątek Andrzeja nie był zbyt wielki. Odziedziczył Zduńską Wolę. W 1454 r. kupił niewielki dział w Paprotni za 30 grzywien $^{14}$. Miał też części w Woźnikach, które jeszcze za swego życia przekazał synowi Janowi. Przed 1453 r. nabyl jako zastaw dzial w mieście Widawie. W $1460 \mathrm{r}$. mial tu jeszcze jatkę ${ }^{15}$. Andrzej zbudowal dom na Porzeczu Grodzkim za murami Sieradza w sąsiedztwie Jana Rogaczewskiego. Król Kazimierz Jagiellończyk uwolnił jego posiadłość miejską od podatków, nagradzając $\mathrm{w}$ ten sposób Andrzeja za organizację pobytu monarchy w Sieradzu na zjeździe generalnym w sierpniu 1452 r. Dom ten sprzedał Andrzej za 19 grzywien Mikołajowi Swędzieniewskiemu z Trzebicznej - mężowi swej siostrzenicy Jadwigi ${ }^{16}$. Nie udało mu się już natomiast korzystnie zainwestować 200 grzywien, które wniosła mu w posagu w $1467 \mathrm{r}$. druga żona - Małgorzata Kunecka ze Strachocic, wdowa po Andrzeju z Będkowa. W 1471 r. Andrzej spisał

${ }^{10} \mathrm{SzZ}$, ks. 4, s. 112-113. Wielokrotnie poświadczony jako jego komornik - zob. SzZ, ks. 4, s. $75,78,145,332,463,513,694,736,944 ;$ SZ, ks. 11, k. 44v, 45v, 57, 58v, 91v, 110v, $121,124 \mathrm{v}, 136,157 \mathrm{v}, 183,199 \mathrm{v}, 288$.

$"$ SG, ks. 8, s. 18,163 .

${ }^{12}$ SG, ks. 8, s. $780 ;$ ks. 9 , s. $48,516$.

${ }^{13}$ Podległe staroście sieradzkiemu sądy grodzkie w Piotrkowie i Radomsku miały własny personel - zob. S. Kutrzeba, Sqdy ziemskie..., s. 103-107.

14 SzZ, ks. 4, s. 1159.

${ }^{15}$ SG, ks. 39, s. 492; SG, ks. 11, s. 6; SZ, ks. 12, k. 783 .

${ }^{16}$ Knigi polskoj koronnoj metriki $X V$ stoletija, wyd. A. Mysłakowski i W. Graniczny, 1. I, Warszawa 1914, nr 180; U. S ow in a, Uklad przestrzenny $i$ spoleczeństwo miasta $w X V-X V I w$, Warszawa-Sieradz 1991, s. 160-161; SG, ks. 37/38, s. 162. 
testament, w którym wyznaczył Mikołaja Grabskiego z Dobrej - podstolego sieradzkiego, i Jana z Grabna - kasztelana konarskiego sieradzkiego, krewnych swej żony z rodu Pomianów, opiekunami nieletniej córki Doroty i jej dóbr dziedzicznych w Zduńskiej Woli ${ }^{17}$. Zmarł po 23 listopada 1473, a przed 21 grudniem 1474 r., pełniąc przez ostatnie 20 lat urząd chorążego mniejszego sieradzkiego ${ }^{18}$.

Za współpracowników Andrzeja należy uznać te osoby, które w $1443 \mathrm{r}$. wypełniały za niego obowiązki sędziego grodzkiego. Nie mogły one pochodzić $\mathrm{z}$ nominacji starosty, $\mathrm{z}$ którym komunikacja byla utrudniona, lecz z mianowania burgrabiego. W tym gronie jedynie Jakub z Kamionacza zostal określony jako protunc iudex castri (3 stycznia 1443 r.). Pozostałe osoby umieszczono na pierwszym miejscu, stąd możemy sądzić, iż w tych dniach przewodniczyly sesjom sądowym: 20 marca - Mszczuj z Rokszyc sędzia ziemski, który w tym dniu wyręczył swego komornika; 26 marca - Maciej z Małkowa; 15 kwietnia i 15 lipca - Jarosław z Zagórzyc; 8 maja - Jarosław z Cieni; 11 listopada - Jakub Pągowski ${ }^{19}$.

$\mathrm{Na}$ drugim miejscu pod względem frekwencji w $1443 \mathrm{r}$. znalazł się Jaroslaw z Zagórzyc. Osobie jego warto poświęcić kilka uwag. Kariera Jarosława wyjaśnia bowiem metodę doboru personelu grodzkiego. Jarosław związany byl już wcześniej z rodziną Koniecpolskich, jako komornik wojewody sieradzkiego Jakuba ${ }^{20}$. Po śmierci wojewody przeszedł na slużbe do jego syna Jana. Należal do rodu Doliwitów. W 1417 r. poświadczony został jako brat cześnika sieradzkiego Stanisława z Silnicy, wsi położonej w sąsiedztwie dóbr Koniecpolskich ${ }^{21}$. Ponadto spowinowacony był z Pobogami z Zapolic i Strońska, wspólrodowcami starosty. W 1417 r. Jarosław razem z Mikułką z Zapolic - synem kasztelana rudzkiego Mściwoja herbu Pobóg, i Dobiesławem ze Strońska poświadczony zostal jako patron kościoła w Strońsku ${ }^{22}$, co można wyjaśnić wcześniejszymi koligacjami z Pobogami. Prócz Zagórzyc posiadał część Chojnego, Zapolic i Strońska. Na Chojnem miała zapisane 150 grzywien jego żona Łucja z Niewiesza - córka wojskiego większego sieradzkiego Chebdy. W 1433 r. Chojne przekazal zięciowi Mikołajowi z Lipnicy i Świerzyn jako posag córki Jadwigi ${ }^{23}$. Synowi swemu Janowi dal w 1443 r. dobra w Strońsku i Chojnem. Na nich oraz Zapolicach Jan zapisał oprawę swej żony Anny w wysokości 300 grzywien $^{24}$. Warto

\footnotetext{
${ }^{17}$ SG, ks. 15, s. 191; SzZ, ks. 5, s. 407, 534.

is Urzednicy..., nr B 40, s. 100.

${ }^{19}$ SG, ks. 7, s. 4; ks. 8, s. 60, 65, 74, 85, 130, 194.

${ }^{20} \mathrm{SG}$, ks. 5, s. 517,653 ; ks. 6, k. 43; SzZ, ks. 3, s. 250.

${ }^{21} \mathrm{SZ}$, ks. $6, k .8 \mathrm{v}$

${ }^{22}$ SG, ks. 3, s. 443.

${ }^{23} \mathrm{SZ}$, ks. 4, k. $115 \mathrm{v}$; ks. 10, k. 4; SG, ks. 8, s. 79.

${ }^{24} \mathrm{SZ}$, ks. 11, k. 80v; SG, ks. 8, s. 585 .
} 
dodać, że również Jan pojawiał się - chociaż niezbyt często - jako asesor sądów grodzkich w latach 1447-1450.

Trzecią osobą odgrywającą ważną rolę $w$ sądownictwie grodzkim był wspomniany już prokurator Jan Rogaczewski. Uczestniczył on w $78 \%$ odnotowanych posiedzeń sądowych, choć przewodniczył tylko 13 sesjom. Wymieniano go wówczas na pierwszym miejscu listy z tytułem prokuratora, jedynie 25 listopada 1444 r. odnotowany zostal jako iudex commissarius ${ }^{25}$. Udział Rogaczewskiego w sądach ziemskich jest niewielki. Pojawił się w roli asesora na rokach sieradzkich 12 razy, na szadkowskich zaledwie jeden raz. Tytułowano go najczęściej: procurator Siradiensis, procurator castri Siradiensis lub procurator Siradiensis generalis ${ }^{26}$. Prawdopodobnie był potomkiem wojewody kęczyckiego Spytygniewa $\mathrm{z}$ rodu Porajów, który to otrzymał od Konrada Mazowieckiego nadanie wsi Dąbrowa Zielona, Rogaczew oraz zaginione dziś Makoszyce (może położone obok Maluszyce?) i Tarlino ${ }^{27}$. Jeszcze w 1405 r. w Rogaczewie występuje Spytek, może ojciec Jana? ${ }^{28}$ Rogaczewski należał do zamożnej szlachty osiadłej na pograniczu sieradzko-małopolskim. Oprócz Rogaczewa posiadal części w Ulesiu i Czepurce. Na tych trzech wsiach zapisał 100 grzywien swej drugiej żonie Annie - córce szlachcianki Malgorzaty Bochartowej z Sieradza. Anna wniosla mu w posagu pola i dom przy ulicy Błotnej ${ }^{29}$. Rozejrzał się także za majątkiem w okolicy Sieradza. W 1449 r. wziąl w zastaw od Piotra z Gorzuch część za 12 grzywien, w 1454 r. kupil za 100 grzywien część w Gorzuchach od Adama - syna Jana Gorzuchowskiego z Sieradza, a w 1456 r. - za 50 grzywien od Zbożka z Rakowic ${ }^{30}$. Na nowe nabytki oraz dom i pola w Sieradzu, sumy zastawne na królewszczyźnie Kawęczynek, przeniósł w 1456 r. oprawę żony, czyli 100 grzywien $^{31}$. Rozbudował też kompleks wokół Rogaczewa. W 1443 r. kupił za 100 grzywien część Olbrachcic od Świętosława z Gołuchowic ${ }^{32}$. Kiedy w 1457 r. jego syn Stanisław zapisywał żonie Łazarii z Borzykowej 300 grzywien oprawy, jako swoją własność wymienił Rogaczew, Gorzuchy, Olbrachcice, Ulesie, Ciężkowice i Borowce ${ }^{33}$. W 1452 r. kupił od Stanisława z Buczka za 100 grzywien Wolę Buczkowską, którą dostala

${ }^{25}$ SG, ks. 8, s. 442.

${ }^{26} \mathrm{SZ}$, ks. 11, k. 79v, 91, 131v; SzZ, ks. 4, s. 209.

${ }^{27}$ Dokumenty kujawskie i mazowieckie przeważnie z XIII wieku, wyd. B. Ulanowski, Kraków 1888 , s. 295, nr 11; J. Bi e niak, Wielkopolska, Kujawy, ziemie leczycka i sieradzka wobec problemu zjednoczenia państwowego w latach 1300-1306, Toruń 1969, s. 112-114.

${ }_{28} \mathrm{~S} . \mathrm{K}$ o zi i r ow ski, Badania nazw topograficznych na obszarze dawnej wschodniej Wielkopolski, t. II, Poznań 1928, s. 72.

${ }^{24}$ SG, ks. 10, s. 387; U. Sow in a, Uklad przestrzenny..., s. 97-98.

${ }^{30}$ SG, ks. 9, s. 853; ks. 11, s. 91, 617 .

${ }^{31} \mathrm{SG}$, ks. 11, s. 608 .

${ }^{32}$ SG, ks. 8, s. 166.

${ }^{33}$ SG, ks. 11 , s. 774. 
w posagu córka Dorota ${ }^{34}$. W sumie zgromadził więc niemaly majątek, nawet jeśli w większości były to części. Warto przypomnieć, że wszystkie inwestycje poczynił w czasie sprawowania urzędu rządcy sieradzkiego. Rozmach inwestycyjny wskazuje pośrednio na dochodowość samego urzędu.

Jan zmarl przed 18 lipca $1457 \mathrm{r}$. Anna wyszła ponownie za mąż za Jakuba z Barczewa - syna Mszczuja. Drugi jej mąż związany był także z sądownictwem grodzkim Koniecpolskiego. W 1472 r. Anna sprzedała Mikołajowi Kotkowi Swędzieniewskiemu część pola w Sieradzu, położonego koło pola mnichów (dominikanów). W $1488 \mathrm{r}$. sprzedała dom przy ulicy Grodzkiej za wilczą szubę i 13 lokci haraszu (jedwabiu), czyli za 10 grzywien $^{35}$.

Niewiele wiemy o pomocnikach Jana. Prawdopodobnie w wykonywaniu funkcji pomagali mu dwaj szlachcice określeni jako jego familiares: Jan Uleski oraz Mikolaj Grad. Ten ostatni za wieloletnie ushugi oddane Janowi otrzymał od jego syna część solectwa we wsi królewskiej Sucha ${ }^{36}$.

Czwartą osobą częściej występującą na posiedzeniach sądów w 1443 r. był Jakub $\boldsymbol{z}$ Pągowa (odnotowany 17 razy). Dwukrotnie przewodniczył sesjom: 11 listopada 1443 i 16 września 1444 r. Prawdopodobnie pochodził z Pągowa należącego w części do Rokszyckich ${ }^{37}$.

Inne osoby pojawily się w 1443 r. już rzadziej i najczęściej $w$ roli asesorów. Jakub z Wilczkowic, Mikołaj Konopnicki zasiadali w składzie sądu 9-krotnie, Maciej z Malkowa - 8 razy, Jakub z Barczewa i Jan z Podłężyc - 7 razy, po 6 razy - Wacław Zadzimski, Jakub Krokocki i Jakub Kamionacki, po 5 - Stanisław z Czartek i Jan Karaś z Sikucina. Należy tu zwrócić uwagę, że wymienione w 1443 r. osoby zasiadające $w$ grodzie, nie występowały wcześniej w tym charakterze za poprzedników Koniecpolskiego. Zmiana starosty lączyła się zatem nie tylko $\mathrm{z}$ wymianą personelu grodu, ale także składu asesorskiego. Oznacza to, że dobór asesorów zależał także od sędziego grodzkiego.

Wplyw Andrzeja ze Zduńskiej Woli na obsadę zastępstw na urzędzie sędziego grodzkiego obserwujemy także w latach, gdy Koniecpolski powrócil już do Polski i częściej pojawiał się w Sieradzu. Niewątpliwie z jego poręczenia sędziami zostali Jan z Kawęczyna (29 czerwca 1444 r.) i Kanimir ze Stęszyc (14 stycznia 1452 r.) wywodzący się z najbliższego sąsiedztwa Zduńskiej Woli ${ }^{38}$. Dobrym znajomym Andrzeja był burmistrz Sieradza Jan

${ }^{34} \mathrm{SG}, \mathrm{ks} .10$, s. 655 ; ks. 13 , s. 32 .

${ }^{35}$ SG, ks. 17 , s. 592 ; ks. 25 , s. 157 .

36 $\mathrm{SG}, \mathrm{ks} .1 \mathrm{l}$, s. $55 \mathrm{l}$; ks. 12 , s. 31 .

${ }^{37}$ SG, ks. 8, s. 194, 405. Jakuba Pągowskiego nie można jednak utożsamiać z Jakubem - synem Mszczuja, gdyż ten pisal się z Rokszyc. Ponadto występował także jako asesor, często wspólnie z Jakubem z Pągowa. Dalsza kariera Jakuba z Rokszyc - zob. Urzędnicy..., nr B 212, B 226.

${ }^{38}$ SG, ks. 8 , s. 343 ; ks. 10 , s. 661 . 
Noskowski - poświadczony jako sędzia grodzki 21 września 1444, 14 czerwca 1447, 3 lipca 1451 i 23 kwietnia 1453 r. Trudno przesądzić, czy bezpośrednio z mandatu sędziego Mszczuja, czy za pośrednictwem Andrzeja zasiadał Noskowski 25 sierpnia 1449 r. loco domini iudicis na rokach ziemskich ${ }^{39}$. Nie ulega zaś wątpliwości, iż to burgrabia ułatwil karierę swemu szwagrowi - Jakubowi z Krokocic. Siostra Jakuba - Jachna - była pierwszą żoną Andrzeja ${ }^{40}$. Jakub jako sędzia grodzki poświadczony został 3 lutego 1444 i 12 stycznia 1445 r. ${ }^{4 !}$ Drugiego protektora pozyskal w osobie Mszczuja, z Rokszyc, którego zastępował w sądach sieradzkim i szadkowskim do $1450 \mathrm{r}$. Zważywszy, że Krokocki przewodniczył sądom w czasie nieobecności tak Mszczuja jak i Andrzeja, nie można wykluczyć udziału tego ostatniego w jego nominacji. Od 16 lutego 1451 r. był już komornikiem starosty Jana Koniecpolskiego i jednocześnie podkomorzego Piotra Zajączka w obu sądach ${ }^{42}$. Ukoronowaniem jego kariery był urząd prokuratora sieradzkiego, sprawowany w latach 1456-1477 z nominacji starosty Jakuba Koniecpolskiego ${ }^{43}$. Z kolei Krokocki wciągnął do współpracy Jana Podłęskiego, którego siostra wyszła za mąż za N. z Mokrzesza, skąd pochodziła także Jadwiga - żona Jakuba. Podłęski jako przewodniczący składu sędziowskiego w Sieradzu poświadczony zostal 29 kwietnia i 11 maja $1444 \mathrm{r}^{44}$, w następnych zaś latach, aż do śmierci w 1472 r., występował jako asesor tegoż sądu. Wielokrotnie, $\mathrm{z}$ reguły tuż za Andrzejem ze Zduńskiej Woli, wymieniono go jako asesora sądu ziemskiego w Sieradzu.

Kolejnego sędziego grodzkiego Świętosława z Żerosławic (poświadczony 19 czerwca 1444 r.) łączyły bliżej nieznane więzi zarówno z Andrzejem ze Zduńskiej Woli, jak i Jakubem Krokockim. W 1460 r. obaj wzięli udzial w ugodzie zawartej po zabójstwie syna Świętosława; pierwszy jako arbiter, drugi jako poręczyciel ${ }^{45}$. Jedynie w przypadku Jakuba Zagórskiego (25 maja 1444 r.) oraz Przecława Pomiana z Woli Rozdziałowskiej (30 stycznia 1451 r.) nie znamy klucza doboru ich na przewodniczących sądu ${ }^{46}$. Pierwszy z nich zapewne pochodził z Zagórzyc, skąd znamy już Jarosława. Nie wiadomo jednak, czy łączyło ich jakieś pokrewieństwo. Drugi był natomiast komornikiem wojewody sieradzkiego Jaranda z Brudzewa, co najmniej od 26 lutego 1448 r., stąd może ów honor ${ }^{47}$.

\footnotetext{
${ }^{39} \mathrm{SG}$, ks. 8, s. 406 ; ks. 9, s. 229 ; ks. 10, s. 527,1019 ; SZ, ks. 11 , k. $225 \mathrm{v}$.

40 W $1478 \mathrm{r}$. Jakub z Krokocic poręczal za swego siostrzeńca Jana, syna chorążego mniejszego sieradzkiego Andrzeja ze Zduńskiej Woli - SG, ks. 20, s. 108.

${ }^{41}$ SG, ks. 8, s. $245,503$.

${ }^{42}$ SZ, ks. 11, passim; SzZ, ks. 4, s. 944 i n.

${ }^{43}$ Muzeum Narodowe w Krakowie, Biblioteka Czartoryskich, Teki Pstrokońskiego, rkps 3346, k. 44; SZ, ks. 12, k. 279.

${ }^{44}$ SG, ks. 8, s. $301,305$.

${ }^{45}$ SG, ks. 12, s. 759.

${ }^{46} \mathrm{SG}$, ks. 8 , s. 315 ; ks. 10 , s. 345 .

${ }^{47} \mathrm{SZ}$, ks. 11, k. 199v.
} 
Personel grodu sieradzkiego rekrutowal się spośród szlachty siedzącej na solectwach i wójtostwach. Przykładem może być tu rodzina soltysów z królewskiej wsi Wągłczew koło Sieradza, znana od 1406 r. Marek z Wąglczewa był w latach $1422-1438$ prokuratorem starostów sieradzkich Piotra I i Piotra II Szafrańców ${ }^{48}$. W 1431 r. kupił za 120 grzywien część wójtostwa $w$ Warcie, który to zakup po raz kolejny świadczy o wysokiej dochodowości tej funkcji ${ }^{49}$. Za starostwa Jana Koniecpolskiego zasiadał jako asesor w sądzie grodzkim. Kilkakrotnie poświadczony został jako iudex commissarius (19 lipca 1445, 5 marca 1453 r.), iudex (4 grudnia 1453 r.), commisarius iudex cause infrascripte per dominum capitaneum iudex in causa hanc (2 lutego $1451 \mathrm{r}$.), wreszcie bez tytułu, ale na pierwszym miejscu składu sędziowskiego, niewątpliwie więc przewodniczył sesji (19 lutego i 19 marca 1450) ${ }^{50}$. Jednocześnie Marek zastępował podsędka w sądzie ziemskim ( 9 listopada $1450 \mathrm{r}$. $)^{51}$. Z czasem zastąpił go $w$ sądzie grodzkim jego syn - także Marek, który dosłużył się urzędu burgrabiego sieradzkiego za starosty Jukuba Koniecpolskiego ${ }^{52}$. Objął go po rezygnacji Andrzeja ze Zduńskiej Woli w związku $\mathrm{z}$ otrzymaniem przez niego urzędu ziemskiego. Po matce Śwį̨tochnie Marek odziedziczył część Sadokrzyc, umożliwiło mu to przejście z grupy soltysów do ziemiaństwa. Wymownym tego świadectwem była sprzedaż solectwa w Wąłczewie w 1474 r. za 150 grzywien Mikolajowi Kaczyńskiemu z Wysokiego Tądowa $i$ kupno Lubnej ${ }^{j 3}$. Żona jego Malgorzata - siostra stryjeczna Mikolaja Swędzieniewskiego, sołtysa królewskiej wsi Trzebiczna - dostała w 1478 r. zapis 200 grzywien na polowie dóbr w Łubnej. Marek pisał się jeszcze jako Wągłczewski z Łubnej, ale jego syn Jerzy zwany Markiem, i wnuk Jan, z przydomkiem Marek, nosili już nazwisko Lubieński ${ }^{54}$.

W sumie przez sąd grodzki w Sieradzu za starosty Jana Koniecpolskiego przewinęlo się 19 osób, które przyjęly na siebie obowiązki sędziego. Rekrutowali się oni $\mathrm{z}$ bardzo różnorodnych środowisk. Byli wśród nich potomkowie urzędników ziemskich, którzy przez służbę u starosty zaskarbiali sobie jego protekcję w późniejszych staraniach o urzędy ziemskie. Z tej grupy wywodził się burgrabia i sẹdzia Andrzej ze Zduńskiej Woli oraz prokurator Jan Rogaczewski. Wokół nich $\mathrm{z}$ kolei gromadził się krąg szlacheckiej klienteli, którą tworzyli sąsiedzi, ale często także powinowaci.

\footnotetext{
${ }^{4 k}$ SG, ks. 1, s. 33 ; ks. 4, s. 621 ; SZ, ks. 10, k. 214-215.

${ }^{49} \mathrm{SG}$, ks. 6, k. $316 \mathrm{v}$.

so SG, ks. 8, s. 665 ; ks. 10 , s. $82,104,353,528,963,1139$.

${ }^{51} \mathrm{SZ}, \mathrm{ks} .11$, k. 268.

${ }^{52}$ Poświadczony z tą funkcją 25 czerwca 1456 r. - SG, ks. 11, s. 679.

${ }^{53} \mathrm{SG}, \mathrm{ks.} 17$, s. $738,760-762$.

${ }^{s 4} \mathrm{SG}$, ks. 20, s. 128; SZ, ks. 13, k. 198v; AGAD, Księgi grodzkie sieradzkie. Inskrypcje, ks. 2, k. 20 ; ks. 6 , k. $146 \mathrm{v}-147$.
} 
Udział w sądownictwie zapewniał im niemale dochody - jak świadczą o tym inwestycje, podejmowane $\mathrm{w}$ czasie lub po zakończeniu urzędowania. W nielicznych przypadkach służba $w$ grodzie stała się profesją rodzinną. Sprzyjało temu dziedziczenie starostwa sieradzkiego przez synów Jana Koniecpolskiego.

6. W okresie sprawowania urzędu starosty przez Jana Koniecpolskiego, w sądzie grodzkim zasiadały jako asesorowie co najmniej 324 osoby, pochodzące ze 153 miejscowości położonych w ziemi sieradzkiej, głównie w powiatach sieradzkim i szadkowskim. Rolę tę wypełniały osoby należące do otoczenia starosty, burgrabiego i rządcy. Świadczy o tym liczba ich wystąpień w różnych sądach, bez związku z własnymi sprawami. Najliczniejszą grupe stanowiły osoby, które pojawiały się na sądach w określonym celu. Przekrój spoleczny tej grupy jest niezwykle zróżnicowany. Zasiadali w sądach urzędnicy innych ziem, jak pisarz kaliski Janusz z Tuliszkowa (25 listopada 1444, 16 kwietnia 1453 r. $)^{55}$, szwagier Przedbora $\mathrm{z}$ Koniecpola, brata starosty, ale także mieszczanie z Sieradza: Michał (18 stycznia 1443 r.), Jan (4 marca 1443 r.), Mikołaj Łysy (26 października i 30 listopada 1444 r.), Gerard (2 czerwca 1445 r. $)^{56}$. Było kilku asesorów duchownych: Maciej pleban w Buczku (24 czerwca 1443 r.), Jan - w Brzeźniu, Mikolaj - w Charlupi (16 września 1444 r.), Michał - w Małyniu (15 lutego 1445 r. $)^{57}$. Nieliczną grupę stanowila szlachta mieszkająca w mieście, do której należeli wójtowie Jan Pierkula - lutomierski, Jaroslaw Kotowski - uniejowski, Mikolaj Szeliga z Janowic - sieradzki i Michał Sromotny z Sieradza ${ }^{58}$. Do najliczniejszej grupy asesorów należała szlachta posiadająca dobra niedaleko Sieradza - zarówno średniozamożna, jak i drobna. Tę ostatnią sprowadzała do miasta nadzieja zwrócenia na siebie uwagi możnych i szansy na poprawę tą drogą swego losu.

\footnotetext{
ss SG, ks. 8, s. 442 ; ks. 10, s. 1010.

${ }^{56} \mathrm{SG}, \mathrm{ks} .8$, s. $23,53,424,441,638$.

${ }^{57} \mathrm{SG}$, ks. 8 , s. $116,405,540$.

${ }^{58}$ SG, ks. 8, s. 46, 55, 116, 305; ks. 9, s. 853; ks. 10, s. 963; U. S ow in a, Uklad przestrzenny..., s. $183,185,194,199$.
} 